ISSN: $1130-3743$

\title{
ENTREVISTA A OCTAVI FULLAT
}

\author{
Interview with Octavi Fullat \\ Entrevue avec Octavi Fullat
}

\author{
Sandra Lilia GÁLVEZ DE RUDZKI \\ Instituto Superior de Investigación y Docencia para el Magisterio. Fracc. \\ Haciendas de Tepeyac, Zapopan, Jalisco, Méxcico, C. P. 45053. \\ Correo-e: sandrarudzki@yaboo.com
}

Doctor Octavi Fullat, he tenido la oportunidad de asistir a muchos de sus cursos, tanto en el continente europeo como en el americano, de leer gran parte de sus libros y tuve el privilegio de haber sido dirigida por usted en mi trabajo de investigación titulado el Planteamiento de la axiología educativa en el pensamiento de Octavi Fullat. Una interpretación de "Viaje Inacabado. La axiología educativa en la Postmodernidad.

De más está mencionar las innumerables veces que nos hemos encontrado y en las cuales hemos tenido la oportunidad de abordar conversaciones que me han sido de gran beneficio para la comprensión de su pensamiento, que, por cierto, se ha enfocado a la educación desde tres principales líneas: epistemológica, antropológica y axiológica. En sus estudios ha subrayado la importancia de identificar los distintos tipos de saberes, resaltando los saberes del sentido, y presenta la educación como un proceso antropológico que se desarrolla a través del tiempo y cuyo principal objetivo es promover una actitud existencial, donde el educando se convierte en sujeto activo del proceso educador. Además, lo que el hombre puede llegar a ser ha sido una preocupación que se refleja en sus estudios axiológicos.

Por otra parte, tengo entendido que el día 20 de mayo de 2003 cumple cuatro años como Profesor Emérito de la Universidad, aunque, por fortuna, eso no significa su retiro de la vida académica, pues precisamente para este año habrá de llevar a cabo diversos viajes académicos por América y Europa. 
Por tal motivo, esta entrevista pretende hacer un recorrido de lo que ha sido su praxis educativa, praxis que deriva del interesante entrelazamiento entre su reflexividad y su historicidad, donde pensamiento y acción se unen para dejarle ante la insatisfacción que le convierte en un eterno caminante. Le agradezco, pues, una vez más su plena disposición para ayudarme a aclarar conceptos que usted ha desarrollado a lo largo de su obra y que han sido de gran interés en el campo educativo.

1. Doctor Octavi, usted es filósofo de la educación, pero también desarrolla actividades pedagógicas, ¿cómo prefiere usted ser definido: como filósofo o pedagogo?

Al pronto se me ocurre que lo más sensato es comenzar con la codificación lingüística. Filósofo es aquel que produce discursos filosóficos. Pero, ¿qué es filosofía? Si nos atenemos al decurso histórico de Occidente —el único que conozco con cierta seguridad-, hay que reconocer que se ha usado el significante filosofia en dos principales líneas semánticas: filosofía como metalenguaje y filosofía como metafísica - discurso más allá de toda posible experiencia. Mi producción escrita ha quedado instalada en el segundo significado de epistemología, antropología filosófica o metafísica y axiología —ámbitos fácticos de mi oficio de pensar - se hallan incrustados en la filosofía inteligida a modo de metafísica.

Ahora bien, paralela a mi ocupación de discurrir filosóficamente, se ha dado otra actividad, jamás interrumpida desde 1950. Me refiero a la vertiente educadora, puesta en práctica fuera y dentro de la academia. Esta práctica ¿es educación o pedagogía? Denomino educador a quien solamente educa valiéndose de teorías que se hallan en el mercado de los saberes. Pedagogo, en cambio, es aquel sujeto que dispone de concepciones personales en el campo educacional -más o menos personales- y que pone en práctica sus ideas en el terreno práctico de lo educativo.

Aceptadas estas precisiones semánticas, debo confesar que soy pedagogo, perteneciendo mis concepciones pedagógicas a la esfera de la filosofía entendida, ésta, como metafísica.

¿Cómo prefiero ser definido? Aquí ingresamos ya en el ámbito del pastoso chocolate con churros o del intrigante caffè ristretto italiano. ¿Qué gusto me hechiza más? Deleites, caprichos, antojos, regostos. ¿Filósofo o pedagogo? Lo dejo por filósofo de la educación. ¿Por qué? Me siento más a gusto. Lo sensual es anterior a todo raciocinio.

2. A lo largo de su carrera usted ba recopilado una amplia obra que se desarrolla principalmente en publicaciones sobre epistemología, antropología y axiología de la educación: ¿cuál de estas líneas considera usted que es la más importante en educación?

Algo es importante o bien como axios - lo digno y justo en sí- o bien a manera de tekbne - saber hacer cosas o saber modificarlas. La primera importancia vale en sí misma y es autónoma; la segunda importancia, en cambio, vale en cuanto que es instrumento para otra cosa, tratándose de una importancia heterónoma, que vive del éxito y del fracaso. En vistas al acto educante, ¿cuál de los tres 
saberes se muestra más importante? La axiología — saber acerca de paradigmas, pautas, valores, dignidades - pende y depende de la antropología filosófica, o discurso metaempírico en torno al ser humano. Si el anthropos acaba en chimpancé hipercomplejo, hipertrofiado, no contamos con otros valores que aquellos que circulan por calles y plazas - los valores son, entonces, los valores que hay en las cabezas de la ciudadanía; los valores, en tal supuesto, no superan el plano de las valoraciones neuropsíquicas y psicosociales. Por el contrario, si el anthropos no queda reducido a positum, a factum, a simple y brutal dato, entonces, y sólo entonces, el valor puede ser más que valoración sociohistórica. Cuando lo humano se intelige como algo más que fenómeno humano, cuando lo humano revienta el corsé de lo científicamente racional, resulta posible entonces plantearse el tema de unos valores que valgan en sí mismos y que no sean banales variables dependientes de los avatares psico-socio-históricos.

He escrito que "valgan en sí mismos"; no he escrito que "valgan por sí mismos". De aceptarse esta segunda salida a la pregunta qué es el bombre, resulta que lo más importante, grave y destacado de cara al acto educante es la antropología-axiología. En cambio, si el ser humano no es más que la adición de sus fenómenos o modos como queda asaltada nuestra sensibilidad, en tal supuesto todo es igualmente importante; es decir, nada importa, siendo todo aburridamente plano e irrelevante. La droga sirve para expulsarse el hastío. Siempre quedará un pedazo de tierra donde nos coloquen cuando lleguemos al muro. El Je regrette d'être né, de Samuel Beckett, se me antoja más lúcido que el apasionado e irrealizable superbombre de Nietzsche.

Queda la epistemología. Ésta constituye un discurso metafísico — más allá de toda posible experiencia - que indaga la constitución de no importa qué experiencia. El saber se pone a meditar sobre qué es saber, cuántos tipos hay de saber y cuál es el grado de fiabilidad de cada uno de dichos saberes. ¿Quién sabe mejor, el matemático, el físico, el cirujano, el psicólogo, el teólogo, el artista, el político, el economista, el ingeniero o, por ventura, el loco y delirante? La epistemología es un organon -instrumento-, diría Aristóteles. Y lo instrumental es mediación o puente, jamás orilla. Los saberes pedagógicos — científicos, teleológicos, tecnológicos- pierden seriedad sin referencia a la epistemología, pero ésta no va más allá de ser bisturí sin alcanzar jamás el estatuto de corazón operado de estenosis mitral.

Cuando se educa, se educa a alguien —antropología - , para algo —axiología-. La epistemología es necesaria, pero jamás suficiente.

3. Usted ha desarrollado trabajos en los que define a la educación en su facticidad como violencia, como lo que es -El atardecer del mal; pero también se ha aventurado en intelegir la educación como lo que puede ser-Finalidades educativas en tiempo de crisis. El ser de la educación lo definió a través del método fenomenológico, en tanto que lo que puede ser la define a través de la bermenéutica. En su libro Antropología filosófica de la educación usted distingue tres tipos de saberes epistemológicos: los formales $y / 0$ axiomáticos, los empíricos y los existenciales $o$ 
significativos. Tanto la bermenéutica como la fenomenología son consideradas como saberes del sentido —saberes razonables. Sin embargo, en el mismo libro usted reconoce que la sociedad actual muestra una gran preferencia por los saberes empiricos y formales porque en ellos prevalece la razón, ¿qué valor tienen en la educación los saberes sentido?

A los seres humanos nos ha costado milenios de sangre y de sudores distinguir entre los saberes de la realidad y los saberes del sentido. El hipopótamo lo ha tenido mucho más fácil, porque, como no ha salido del bulto de lo real, para él no se da la realidad. Estímulo-respuesta, nada más. Tal como acontece con la diminuta Drosophila melanogaster. Pastosidad de lo que hay y en el seno de lo que hay. Sin conciencia, o apercepción, del mundo como realidad. Las ciencias ocupan su tiempo escribiendo secuencialmente — con revoluciones científicas- acerca de lo pastoso e indefinido del mundo. El relato científico en torno al universo es de suyo interminable, siendo siempre, además, hipotético. No se cuenta con verdad científica, sino con verdades científicas, las últimas dejando mal paradas a las anteriores. Karl Popper ha cubierto inteligentemente estas vergüenzas e indecencias intelectuales, aunque sin suprimirlas.

Al estudiar, yo, los hechos educativos, me he acercado a ellos en cuanto que se ofrecen a modo de facticidad. ¿Qué he descubierto? Que todos tienen en común el ser violentos. La violencia configura el sustrato que los distingue. Agresividad entre padres y vástagos, y entre los mismos descendientes. Desafuero mutuo entre profesores y alumnos, y entre los mismos alumnos. La violencia centra al acto educativo. Los saberes de la realidad educadora topan con la violencia de igual suerte como el modelo atómico de Bohr (1913) encuentra el núcleo, compuesto de protones y de neutrones. La educación, como lo que es, no va más allá de ser violencia, tan tecnificada como se quiera, pero desafuero a la postre.

En la línea de Dilthey, además de las Naturwissenscbaften — saberes de la realidad, las he llamado- se colocan las Geisteswissenschaften - o saberes del sentido, según mi léxico-. Una cosa es el ordo factus - lo ya hecho- y otra harto diferente es el ordo faciendus - lo que hay que hacer-. Una cosa son los actus bominis - la banal facticidad humana-y otra los actus bumani-aquellos actos que engendran lo humano en el hombre-. Desde esta segunda perspectiva he abordado también los fenómenos educantes; ya no interesa, entonces, la educación que hay, sino aquella que tendría que haber. No preocupa ahora la realidad educativa, sino el sentido de la educación. No la educación que hay, sino la educación posible. A la violencia educativa llegué con el método fenomenológico; en cambio, la hermenéutica gadameriana me ha resultado útil para hacerme con las posibilidades educacionales.

Las gentes dejan la ciencia para los científicos y la tecnología para los tecnólogos, aunque, esto sí, recurren al médico, a la farmacia y al quirófano cuando andan en apuros. Pero ¿pensar?; que piensen los demás. Yo pago y me sirvo de sus averiguaciones y de sus habilidades. Lo mío, dicen, es vivir del corazón y de las 
glándulas suprarrenales. Y allá como acabe todo, porque a la postre siempre termina todo. Hasta tal extremo es esto así que en ocasiones me ha asaltado el $d u b i o$ de si contamos con algo que sea realmente algo en vez de escurridizo vagar.

Me dices, Sandra, que la sociedad actual valora tan sólo los saberes empíricos, aquellos que acaban en utilidades, en pastillas que ayudan a dormir, en propaganda que hace vender incluso verdaderas porquerías como la Coca-Cola, en bombas inteligentes que pretenden dominar el mundo, en técnicas mediáticas que controlan los mores públicos, en dietas que ayudan a adelgazar... ¿Qué papel otorgar a los saberes del sentido en la práctica educativa? Confieso que este extremo no se valora ni tan siquiera en la academia universitaria, donde la tecnología educativa y la pedagogía aplicada gozan de mayor respeto que, pongamos por caso, la teoría de la educación o la filosofía de la educación, que con misericordia se toleran, sobre todo esta segunda. Stultorum numerus infinitus est, según se lee en el Antiguo Testamento en la versión de San Jerónimo. "El número de los imbéciles es incontable». La cantidad, por mucho que engorde, jamás pasa a ser calidad. Una película taquillera, de entrada es una mala película. Todos han ido a verla. Stultorum numerus infinitus est.

Los valores del sentido no se valoran. Facticidad. De aquí no se sigue, en lógica, que no sean valiosos. Del hecho que la puerta esté cerrada no puede deducirse que tenga que permanecer cerrada. ¿Cómo podemos educar unos vástagos o unos alumnos sin disponer de un paradigma humano que sea el sostén de valores que operan como teloí, como finalidades, hacia los cuales orientarse? Al dromedario le bastan los estímulos para dar respuestas; el ser humano, en cambio, queda pasmado ante la estimulación y necesita repertorios culturales - entre los cuales están los sentidos del vivir - a fin de responder a su circunstancia o rededor.

\section{4. ¿Cómo define la educación?}

El término educación ha funcionado de manera polisémica. Las definiciones obtenidas se han presentado variopintas y con frecuencia han sido más descargas emotivas que discurso que se vale de la denotación lingüística. Acepto que se utilice la palabra educación para realizar psicoterapias; es cosa difícil conservar la salud mental. Pero estimo que no es suficiente; por esto me he esforzado en alcanzar cierta claridad en este asunto. Para empezar sostengo que los procesos educativos son específicos del ser humano; el hombre es el único animal educandum -bestia que tiene que ser educada si debe alcanzar el estatuto humanosapo, ni la pulga ni tampoco el elefante o el gorila tienen que someterse a educación a fin de abrazar la categoría de sapo, de pulga, de elefante o de gorila. Los animales son educables, pero en modo alguno educandos. El circo —un elefante encima de un taburete- y el medio doméstico y urbano - un can, consolador del psiquismo de una fémina, aprendiendo a no mearse en casa-constituyen pruebas de que las bestias son educables, pero, desde luego, no son educandos; me atrevería a soltar que el elefante del Serengeti —en Tanzania- y el perro salvaje 
son con mayor propiedad elefante y perro que los desgraciados que viven educados en un circo y en una casa de vecindad.

Los procesos educativos humanos se montan encima de un concreto código genético modificado por procesos madurativos - conjunto de transacciones entre dicha herencia biológica y el medio no humano constituido por alimentación, agua, clima, aire respirable... Los procesos educativos vienen luego - conceptualmente-, aunque queden inexorablemente imbricados con la genética y con los procesos madurativos. ¿Cuándo hace aparición el primer acto educante? En el preciso instante en que a un grupo zoológico no le basta la herencia biológica para tirar adelante. Cuando han aparecido productos culturales, no transmisibles a través del código genético, no queda otra salida para la sobrevivencia de la nueva especie que valerse de los procesos educativos. ¿Qué es en este significado, educar — "educación-aprendizaje" o learning?, un conjunto de transacciones entre un código genético, moldeado por procesos madurativos, y un ámbito humano o civilización. En este sentido el acto educador implica proporcionar informaciones, despertar actitudes y facilitar la adquisición de habilidades. De tal guisa se ingresa en una civilización - cultura o manera de ver el mundo, técnica o manera de modificar el mundo, e instituciones o modos de instalarse colectivamente en el mundo-. Ciencias y tecnologías de la educación entienden en tales menesteres.

Si la educación humana quedara reducida a lo anterior, resultaría dificultoso discernir entre doma de animales y educación del ser humano. Ahora bien, aunque no pueda probarse - en el significado de prueba empírica tal como ya la entendió Galileo-, sí se puede suponer la existencia, en el hombre, de realidades no reducibles a fenómenos o experiencias. La tradición occidental - ya desde judíos, griegos y romanos - se ha referido a lo metaempírico en antropología. Así se ha escrito sobre el alma, el espíritu, el yo, la conciencia, la libertad, la obligación, la culpabilidad, etc. Si dicha esfera no sometible a la experiencia empírica existe, en tal supuesto, y sólo en tal supuesto, adquiere significación referirse a una segunda modalidad educadora, que he denominado procesos educativos liberadores. Porque el ser humano no solamente disfruta de vivencias, sino que además puede tomar conciencia de las mismas, quedando a la vez pegado y separado de las mismas - el yo vive el amor, soldado o adherido a él, y el mismo yo se apercibe de su vivencia amorosa proyectándola al extremo de su acto de apercibirse de ella-, porque el ser humano, decía, se descubre escindido entre un yo viviente y un yo que proyecta lo vivido como algo distinto de lo vivido, queda abierta la esfera de la libertad radical. La libertad, hontanar de responsabilidad y de culpabilidad ontológicas, abre a la esfera de la creatividad. Cum haec ita sint-de ser las cosas así-, que gritaba Cicerón en el Senado, entonces me pongo a platicar de la educación liberadora; liberarse, en lo que cabe, de nuestras informaciones, afectos y psicomotricidades. Liberarse, empero, ¿en vistas a qué? En este punto se instala la creatividad que imagine nuevas sociedades y nuevos modelos antropológicos considerados más humanos. Tal esfuerzo creador no es asunto individual y narcisista, sino resultado de diálogo, diálogo que únicamente adquiere respetabilidad si 
se arranca del acto de conciencia que lo coloca todo en la pantalla de enfrente, en vez de quedar los dialogantes esclavizados por sus seguridades y mesianismos.

\section{Usted ha señalado que antropología y pedagogía constituyen una circularidad enriquecedora, ¿en qué consiste esta circularidad?}

El gnotbi seauton —conócete a ti mismo o cognosce te en latín-que se repetía en los muros del santuario griego de Delfos, y que tanto impresionó a Sócrates, es el grito que especifica a esta bestia extravagante que es el ser humano. ¿Qué es el hombre?, "un animal que pregunta: ¿qué es el hombre?». El delfín jamás lanza interrogante tan estrafalario; ninguna vez pregunta: ¿qué es el delfín? Si alguien me asegura que sí formulan cuestionamientos de este tipo, dichos simpáticos animales, le responderé que, en todo caso, lo llevan tan escondido que no han dado ninguna muestra de ello y que, por consiguiente, carece de interés el asunto. Siempre repitiéndose monótonamente a menos que nos entrometamos en sus vidas, tan naturales ellas, de suyo.

¿Qué es el hombre?; no contamos con el anthropos eterno, que reside allende el tiempo y el espacio. Que nos perdone Platón con sus eide-plural de eidos, realidad ideal subsistente, separada de lo sensible, inmutable, eterna. No pertenezco a la confesión platónica con manifestar que sus diálogos me han estimulado en más de una ocasión. ¿Qué es el ser humano, pues? La inacabable sucesión de respuestas que los hombres se han proporcionado. El antbropos consiste en historia del antbropos. Y ¿qué nombre le damos a la tarea de producir al ser humano?, ni más ni menos que paideia, vocablo que Cicerón tradujo genialmente al latín con el significante bumanitas, y que en castellano se ha vertido de forma patosa y desgarbada con el vocablo educación. Paideia fue civilización y civilidad, aquello que hace que el hombre prosiga y no se detenga. El antbropos es aquello que será y que todavía no es. El ser humano consiste en tarea, faena, empresa; es decir, en educación. Y esto es así tanto si se le considera como individuo que como acontecimiento histórico. Anthropos y paideia, ser humano y proceso civilizador, se exigen mutuamente hasta tal extremo que, de suprimir uno de los dos núcleos, el otro se disipa, evapora y extingue. Circularidad esencial.

6. Usted explica que no se puede concebir la educación al margen de la Antropologia. Define también que hay Antropología Física, Cultural y Filosófica. ¿Por qué se centra su interés en la Antropología Filosófica y en qué consiste su relación con la educación?

Una antropología - de anthropos, lo humano, y de logia, conjunto de palabras o pensamientos sistemáticos en torno a algo-, una antropología, decía, constituye un discurso ordenado - el logos griego implica verdad obtenida gracias a argumentación concluyente. Tal discurso ordenado, para el caso, aborda al ser humano. Siendo la educación antropogénesis o engendramiento del hombre, salta a la vista que no es procedente referirse a educación sin apuntar simultáneamente 
a antropología y viceversa; no resulta practicable un habla acerca de lo humano como, al propio tiempo; no vaya acompañada de la realización de lo antropológico. Antropología y educación son reciprocantes.

Ahora bien, el saber antropológico en la actualidad se ha objetivado en tres modalidades harto diferenciadas: antropología física, antropología cultural y antropología filosófica. Bien es verdad que la mayoría de veces el significante antropología viene usado en el significado de antropología cultural. Pero esto no va más allá de ser un hábito o muletilla; es decir, carencia de riqueza lingüística. La verdad es bastante más compleja.

Cuando Galileo se sirve de scienza nowva en su libro Discorsi e dimostrazioni matematiche intorno a due nuove scienze (1638) se apercibe de que su práctica científica es distinta de lo que venía haciéndose desde los griegos bajo el nombre de episteme-vecchia scienza-. La nueva concepción galileana de ciencia descansa sobre la observación y ordenación generalizada de fenómenos. Se ha introducido una fractura mayúscula en epistemología. Unicamente hay ciencia de fenómenos - lo observable sensorialmente; el resto serán saberes metacientíficos. Dejando de lado, ahora, las ciencias axiomáticas — matemáticas y lógica_, resulta que hacen aparición dos tipos de saberes: los científicos, o de la realidad, y los nocientíficos o del sentido.

A partir, particularmente, del siglo XIx van surgiendo las ciencias sociales humanas, que también pertenecen al ámbito de los saberes de realidad aunque no disfrutan de la contundencia de la física. Así las cosas, nos descubrimos delante de dos modalidades del saber: los saberes de la realidad, o científicos, que son o bien naturales o bien sociales, y los saberes del sentido, no-científicos o más allá de los fenómenos o experiencias sensibles.

Estas tres presentaciones epistemológicas han dado pie a los tres tipos actuales de antropología. La antropología física es ciencia empírica de la naturaleza y aborda temas anatómico-fisiológicos de lo humano. Tipos de cerebros - e. g. braquicéfalos y dolico-céfalos-, diversidad de razas..., etcétera. A partir de Linneo se estudia al ser humano, desde tal perspectiva, como una especie biológica más.

La antropología cultural es también ciencia empírica, pero social o humana; trata cuestiones específicamente humanas -el páncreas lo tenemos en común con los restantes mamíferos; lo específico humano se encuentra en la cultura - las ideas, técnicas e instituciones-. Boas, alemán americanizado, en su obra Race, Language und Culture (1940) pone las bases de la antropología cultural que, en otras nomenclaturas, coincide con la etnología. Sapir, Mead, Lévi-Strauss son otros representantes considerables de la antropología cultural.

Tanto la antropología física como la cultural son ciencias empíricas, aunque la primera se hace con el hombre en cuanto que pedazo de naturaleza, mientras que la antropología cultural estudia al hombre en los productos socio-históricos de éste. El enfoque de la antropología filosófica, llamada por algunos metafísica, es fundamentalmente distinto. No se consideran los fenómenos humanos - asunto propio de las ciencias-, sino que uno pretende hacerse con el sentido, o significado, de 
dichos fenómenos. Así, una cosa es que el ser humano viva la erótica y otra diferente es indagar el para qué del eros humano; un asunto es vivir en sociedad y otro distinto es el significado que esto tiene; morir en el seno de un grupo con sus ceremonias fúnebres constituye tema aparte del que se dispara cuando interrogamos por el sentido del expirar humano. La antropología filosófica vive de leer los fenómenos del hombre más allá de todo posible fenómeno. No se trata de captar y organizar fenómenos antropológicos - tarea de las ciencias-, sino de interpretar o someter a hermenéutica - poco importa, ad casum, que ésta sea la de Gadamer o bien la de Habermas - los hechos humanos, tanto los zoológicos como los culturales.

Me planteas, Sandra, la relación entre procesos educativos y antropología filosófica. Pues, mira: tu curiosidad pone el tema de si el anthropos queda reducido a facticidad, a datos, a posita, como sostenía Comte, o, además de todo esto, es preciso imaginarse también al ser humano como deber-ser. El positivismo redujo la totalidad del anthropos a hechos y, puestos a conocer éstos, redujo el hombre en última instancia a enunciados de hechos. Los restantes discursos pasaron a ser quiméricos. Observación y verificación; nada más. Pues bien, la antropología filosófica piensa al hombre de modo tan poco científico que tenga, aquél, la posibilidad de protestar, más allá de la voz del asno, contra Auschwitz o contra la dictadura de Stalin.

¿A qué se reduciría una educación amputada de antropología filosófica?, a doma y domesticación de bestias, aunque éstas sean humanas y por tanto con más neuronas en el cerebro y con mayores posibilidades en el gran teatro del mundo. La antropología filosófica le permite al proceso educativo no liquidar las posibilidades más exaltantes del hombre como son la ética, el amor, la religión, el arte y la amistad.

7. En su libro Final de Viaje usted señala que educación y bombre forman un circulo bermenéutico fundamental, pero ¿es posible definir al bombre al margen del tiempo?

No está a nuestro alcance ni actuar, ni sentir, ni tampoco pensar como no sea temporalmente, según secuencias. Kant en Kritik der reinen Vernunft (1781) deja ya establecido que el tiempo es la condición sensitiva universal — no así el espacio- que hace posible que algo se me manifieste sensitivamente. El tiempo hace que la cosa sensible se me exprese como objeto percibido.

La noción de tiempo conlleva la experiencia humana básica de la sucesión. Tanto si se presenta la sucesión con una línea recta -caso abrahámico del judaísmo- como si se la representa a modo de círculo - caso del regreso de Ulises en la cultura griega-, la conciencia humana no puede menos que hacerse cargo sucesivamente de los acontecimientos encadenados. Además, el hombre constata la imposibilidad de modificar el orden temporal, de suerte que comprobamos que los sucesos van del pretérito hacia el porvenir y jamás a la inversa. Las relaciones de sucesión han dado paso a la idea de dirección del tiempo. ¿Hacia 
dónde se encamina el ser humano?, ¿cuál es el telos, salida, cumplimiento, realización o consumación del anthropos? El hombre toma conciencia de sí como temporalidad sucesiva y, en este momento, salta el cuestionamiento sobre la dirección a seguir, sobre el sentido del fenómeno humano.

No, Sandra; no es posible definir al hombre al margen del tiempo, pero reconocerás que la experiencia temporal trae de suyo el sentido del tiempo y, con él, el mismo sentido del ser humano. Las respuestas a esta última pregunta son ad infinitum, y jamás pronunciamos la última. La hermenéutica, como la entiende Gadamer en Wabrheit und Methode (1960), es una lectura y una relectura interminables de relatos. Lengua y lenguaje configuran un movimiento ininterrumpido de lo finito hacia lo infinito. No se puede abrazar a éste porque reside fuera del tiempo, pero la búsqueda de sentido define al anthropos. No se concibe a éste al margen del tiempo, pero sí como esfuerzo inacabable de salir de lo temporal. Quizás se deba a esto el que Sartre, aunque de manera un tanto precipitada, definiera al hombre como "la pasión inútil de hacerse dios".

\section{8. ¿Cómo define la antropogénesis?}

Esta pregunta anda particularmente imbricada con la cuestión del tiempo antropológico. El ser humano no es algo hecho; es quehacer. En consecuencia, consiste en temporalidad, de suyo no clausurable. ¿Cómo delimitar, definir o precisar los lindes o confines de la antropogénesis? Ésta, la antropogénesis, se ciñe, de fiarnos de la etimología, a engendrar lo humano. Pero parece sensato sostener que el hombre no está concluso ni en una fantaseada idea eterna de hombre, ni tampoco parece concluido en el seno de los procesos históricos. Me atrevería a decir que el anthropos, más que ser esto o lo de más allá - nos sobran omniscientes mesiánicos—, se define precisamente como antropogénesis. ¿Qué es, por tanto, el ser humano? Aquel animal que tiene que hacerse hombre. No hay anthropos; disponemos solamente de humanización. Humanizar, ¿según qué parámetros?; incluso éstos constituyen tarea humana. Los valores antropológicos no están dados de entrada; tenemos que ponerlos dolorosamente a través del tiempo histórico. La antropogénesis resulta ininteligible sin referencia a la historia, la cual acaso pase a ser un síntoma visible del ser como temporalización. La autopoyesis humana fue ya ocurrencia renacentista; Giovanni Pico Della Mirandola en su libro De bominis dignitate (1486) afirma que el ser humano es el único árbitro de sí mismo. No sucede lo mismo con las bestias. El hombre acaba en antropogénesis; ¿cómo hacernos cargo de faena tan singular y a su vez tan grave de cara a la actividad educante? Ya, antes, Sócrates en el diálogo platónico Apología Sokratous, habla de la siguiente guisa en el último tercio del siglo $\mathrm{V}$ a. C.:

Calias, si tus dos hijos fueran potros o becerros, tendríamos que tomar un cuidador de ellos y pagarle; éste debería hacerlos aptos y buenos en la condición natural que les es propia, y sería un conocedor de caballos o un agricultor. Pero, puesto 
que son hombres, ¿qué cuidador tienes la intención de tomar? ¿Quién es conocedor de esta clase de perfección, de la humana? (20, a-b).

La naturaleza del hombre no es un dato, sino a lo sumo una tendencia poco precisa. El análisis que Heidegger ha realizado del Dasein - el ente humano-en Sein und Zeit (1927) entendiéndolo como posibilidad, como existencia -ex, sistere-, pone luz al interrogante en torno a la antropogénesis. La esencia de lo humano es tener-que-ser mientras los entes intramundanos constituyen datos. El Dasein es un Un-zubause, un forastero; está en el mundo según la Unbeimlicbkeit, la extranjería. La temporalidad es lo primario en el ser humano; la temporalidad es ekstatikon, es ser fuera de sí. El Dasein queda abierto mientras la muerte no llama a la puerta. El ser humano no disfruta de caminos trillados o bien reales, sino que únicamente tiene a mano el Feldweg - camino campestre-y el Holzweg - camino forestal. Lo humano reside en hallarse en camino sin contar con rutas claras y distintas. Escribe Heidegger en Was ist Metaphysik (1929):

La Nada es la condición que hace posible la revelación del ente, como tal, para el Dasein — realidad humana-. El hombre pasa a ser el centinela de la Nada.

A pesar de que Agustín de Tagaste le dedica al tema del tiempo - tan antropológico en manos de Agustín- los capítulos del libro XI que van del 13 al 28, no puede menos que confesar su perplejidad ante lo temporal. ¿Qué es el tiempo?:

Si nemo a me quaerat scio; si quaerenti explicare velim, nescio.

La antropogénesis acaba en aventura y embarque porque el tiempo, que el ser humano es, aparece como algo recóndito y arcano. No de otro modo lo vislumbra San Agustín en el capítulo XXI del libro XI:

¿En qué espacio de tiempo medimos el tiempo que pasa? ¿Acaso en el futuro, en función del cual pasa? Pero lo que aún no es no lo podemos medir. ¿Tal vez en el presente, por donde pasa? Pero tampoco podemos medir el espacio que es nulo en el presente. ¿Será, por ventura, en el pasado que ya ha sobrepasado? Pero lo que ya no es no podemos medirlo.

El hombre-temporalidad es más cuestionamiento que certidumbre. La antropogénesis acaba en trabajo, empeño, solicitud y, sobre todo, en generosidad. La antropogénesis transforma la experiencia de la historia en algo con sentido. Y el sentido lo constituimos lingüísticamente y, de tal suerte, comprendemos el mundo y ayudamos en su construcción. Al fin y al cabo la hermenéutica se intelige desde el diálogo; es decir, desde la tentativa de entendimiento.

Tu pregunta, Sandra, parecía de vocabulario, pero ya has podido caer en la cuenta de lo grave que era.

9. En su libro Antropología filosófica de la educación usted dice que parece indiscutible que el ser bumano pertenece a la naturaleza, ocupa espacio y también 
tiempo". Más adelante subraya una triple dimensión según la cual el hombre es biologia -sarx-, cultura-psykhe--y biografia - pneuma-. Define que sarx, el elemento psicobiológico, se sitúa en el paleocórtex-cerebro biológico-; ubica a la psykhé —el elemento sociocultural - en el mesocórtex-cerebro social-; por último, señala que el pneuma - que corresponde al elemento espiritual, y en el que usted incluye los conceptos de conciencia, libertad, creatividad y responsabilidades colocado por los neurólogos en el neocórtex-cerebro creador-: ¿de qué forma estas dimensiones se vinculan con el tiempo del hombre?

Estimo atinado, mientras no cambie de parecer, inteligir al antbropos como sarx, como psykbe y como pneuma, para servirme de terminología griega aunque sólo sea porque ya nadie la utiliza. Me siento incómodo si sólo soy una pieza del rebaño social. Globalización y mass-media no van conmigo. ¿Que me quedaré sólo?, qué más da, con tal de no ser un borrego más de la sociedad.

Los neurólogos, así Henri Laborit en Biologie et structure (1968), se han referido a paleocórtex, a mesocórtex y a neocórtex, viendo, en estas tres potencialidades del cerebro, conductas que yo organizo bajo los términos griegos de sarx, psykhe y pneuma. En la complexificación evolutiva del sistema nervioso hizo aparición primero un cerebro elemental - paleocórtex-, el de los reptiles, que vive sólo de la herencia biológica colocándose de lleno en el tiempo presente. Se vive del contorno y para el contorno. Millones de años después hubo que contar ya con un cerebro mucho más complejo, el de los mamíferos por ejemplo, que se ha denominado mesocórtex. Ahora ya vale, no sólo el tiempo presente, sino igualmente el pasado, lo aprendido después de nacer. Por último, con la especie humana y sus inmediatos antecesores el cerebro se enriquece con el neocórtex. Éste se enreda ya con el futuro y labora con proyectos. Estas cosas las he contado en diversos libros míos resultándome útiles en vistas a la comprensión del enmarañado proceso educativo.

Con los años esta comprensión tripartita del fenómeno humano y del fenómeno educador me vino estrecha, no pudiendo respirar holgadamente. En mi libro Antropología filosófica de la educación busqué una salida airosa al estrangulamiento intelectual. Introduzco allí un concepto nuevo, el de ruah, sacado de la literatura bíblica hebrea. No se corresponde al pneuma griego, privilegiándose la desmesura y la a-racionalidad. ¿Atrevido?, pues sí. Igual me califican de mentecato y necio. Aunque a mi edad tales extremos me dejan aletargado, diría, sin embargo, que no hay para tanto. Al fin y al cabo la correspondencia entre las palabras y el bulto del mundo es pura subjetividad. Lo que importa es que el modelo antropológico resulte útil si queremos hacernos cargo de conglomerados de fenómenos. Se me antoja que añadirle al modelo tripartito anterior la imagen del ruab judío como lo extravagante y lo opuesto a la sensatez grecorromana, resulta por lo menos interesante.

¿De qué forma estas dimensiones se vinculan con el tiempo del hombre? Bajo la imagen de sarx se cobija todo lo presente, sea estímulo, excitación o respuesta; es decir, lo inmediato, lo a pedir de mano. El vocablo psykhe me vale para referirme 
a nuestro pretérito acumulado, retenido, en la memoria. Pneuma me resulta útil para apuntar al futuro, para referirme a lo humano como expectativa - como espera, no como aguardo-. Decisiones, proyectos, fantasías encuentran su lugar en el pneuma. Pero, ¿qué hago con el ruah?; éste me permite escapar de la seriedad del tiempo poniéndome a entender anthropos y paideia, también, como insensateces, desmesuras, excesos e intemperancias. Con los años la sola racionalidad ha terminado por asfixiarme. Ya ves, Sandra; cuando pequeños, vivíamos con poca razón y ahora, con tanta memoria cargada en la biografía, añoro la dicha que proporcionaba el no ser racionales o, por lo menos, el serlo muy poco. Historia - pretérito, presente y futuro - y eternidad - desmesura e insensatez-

\section{De las dimensiones citadas ¿cuál considera usted que es el punto de partida para toda educación? Y ¿puede una existir al margen de otra?}

La expresión punto de partida no anda libre de ambigüedad, pero desde luego incluye la idea de dar explicación de algo. En el siglo iv a. C. Aristóteles ya en su obra ta physika se refiere a los arkhai - principios-y a los aitiai -causas- de cuanto aparece y de cuanto estudiamos, unos y otras explicando por qué surge algo. Séneca en una de sus Epistulae - entre el 62 y el 65 - traduce el texto aristotélico al latín refiriéndose a cuatro causas: materia - aquello con lo cual algo se produce-, opifex - el autor del producto-, forma - lo que especifica y distingue, lo producido, de otros productos-y, por último, el propositum -el modelo mental en que se inspiran la producción y el mismo productor.

¿Cuál es el punto de partida para toda educación? De entrada afirmaré que contamos con cuatro puntos de partida y que los cuatro resultan indiscutibles, aunque desempeñen papeles distintos. Para iniciar la educación se necesita herencia biológica modificada por el medio natural — valga el término sarx para señalar tal extremo-; ésta es la materia de que habla Séneca. Un segundo punto de partida es el opifex, el artesano, el educador. El concepto de psykhe vale tanto para designar a los elementos educadores como a la acción y al resultado de los mismos. El tercer punto de partida es el pneuma, lo específicamente humano, que distingue el resultado de la actividad educadora de otras posibles actividades. Séneca señala esta tercera causa con la palabra forma, que traduce el término griego morphe. En la traducción que Séneca hace del texto aristotélico hay una cuarta causa explicativa de que algo sea así o asá; es el propositum o ideal a seguir por parte de los actores. Platón habíase referido a modelo ejemplar — eidos-, que puede perfectamente inyectarse en el concepto aristotélico de propositum o causa final. Mi noción de ruab abraza aquel modelo metahistórico que anima en última instancia a los procesos educantes, que los hechiza y atrae. Cuatro son, pues, los puntos de partida de una educación englobante y no amputada.

Con todo, no pierdas de vista, Sandra, que no pretendo con estas nomenclaturas desvelar el secreto de la realidad, sino que me ciño a hablar de lo educativo quoad nos; es decir, organizar la esfera de lo educacional de tal suerte que 
nos resulte inteligible y, a su vez, entusiasmante. Yo ignoro qué cosa sea lo real. Tampoco el físico sale mucho más airoso. La eficacia no es criterio indiscutible de saber riguroso.

11. Si sarx se refiere a la biología, jen qué consiste la diferencia entre el hombre y los demás animales?

Entiendo tu pregunta en el sentido de qué diferencia puede establecerse entre la biología humana y la biología de otros mamíferos, siempre, claro está, en cuanto que elementos biológicos. Me he valido en mis escritos del vocablo griego sarx. No siempre lo he distinguido de otros significantes helénicos emparentados, porque mi atención no era tanto precisar el léxico griego cuanto tomar un vocablo que llamara la atención hacia un concreto ámbito semántico. Pero tú me invitas a ser más explícito.

Prestando atención a la terminología griega a lo largo de varios siglos - desde Homero hasta los textos neotestamentarios- y sin precisar ningún escritor, considero aceptable distinguir entre soma, zoe o zoion, y sarx. La palabra soma-corpus en latín - señalaba a lo que se encuentra circunscrito, delimitado, en una extensión del espacio. Sería principalmente la materia no viva. El significante zoe, vida biológica, apunta a la esfera de los seres vivos; éstos no sólo se hallan distentidos en el espacio, además tienen organizadas unitariamente todas las partes del cuerpo. Por último sarx significó la carne humana o manera como el hombre es somático y zoético. El zoe de la ballena no coincide con la sarx, que según el evangelio atribuido a Juan Evangelista sirvió para la encarnación de la segunda persona trinitaria. Recordemos el texto:

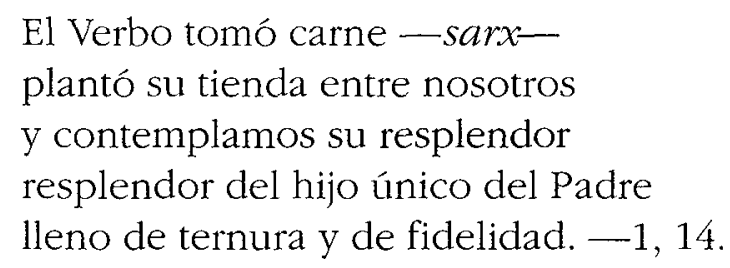

El zoe de la ballena no va más allá de ser cuerpo-objeto, cuerpo para los demás, para que lo vean, oigan, toquen, huelan e incluso gusten. No, así, la sarx; ésta es carne humana, cuerpo-propio, sentido y experimentado como mío. La sarx se distingue porque no acaba en espectáculo, sino en anábasis, en retraimiento o ensimismamiento. La carne humana es carne de un yo, la de Jorge o la de Montserrat. El zoe de la ballena es mostrenco, de nadie; en todo caso será primi capientis - del primero que lo agarre-.

Aparte lo dicho - la dimensión corpórea o soma sarkikon-, el ser humano emerge entre las restantes bestias por no ser sólo bestia, por disponer pongamos por caso, de pneuma, según el uso que de esta palabra hace Pablo de Tarso en la primera carta a los cristianos de Tesalónica: 
Que pneuma-espíritu-, psykbe —alma-y sarx — cuerpo-, todo vuestro ser se revele sin tacha en el advenimiento de Jesús, el Cristo. - 5, 23.

12. En su artículo Presupuestos antropológicos de la educación moral usted dice que "el hombre se encamina a la muerte, construyéndose la vida biográfica desde la conciencia”. En este recorrido ¿qué es primero: la acción o el pensamiento?

Utilizamos la palabra vida tanto para referirnos a la vida de las cebras como para dar a conocer la vida del arquitecto catalán Gaudí. La primera es vida biológica; la segunda es vida biográfica. La primera se interesa por la reproducción, la nutrición, el crecimiento, la decrepitud y la muerte, como asimismo intenta hacerse cargo de las diversas secuencias y ritmos vitales convirtiéndolos en sistema a base del modelo de homeostasis. Detrás de la vida de las cebras no hay nada; la vida biológica se reduce a escaparate de fenómenos. No así la vida biográfica de Antoni Gaudí; detrás del espectáculo que éste ofreció y sigue ofreciendo, bulle la conciencia personal de Gaudí. La vida biográfica es de alguien, en contra de la vida biológica, la cual es de nadie. Por tan elemental razón, únicamente las vidas biográficas quedan sometidas a la moral. Husserl en Ideen zu einer reiner Phänomenologie (1913) afirma que la esencia de la conciencia es la intencionalidad. El yo consciente de sus vivencias coloca delante de sí a su personal vida, con lo cual ésta deja de ser adición de secuencias pastosas pasando a ser actividad que busca su sentido y dirección.

En el recorrido biográfico, me preguntas, ¿qué es primero la acción o el pensamiento? Primero puede entenderse en el tiempo o bien en importancia. Me inclino a pensar que en el decurso temporal la acción es primera; en cambio, en cuanto a importancia, el pensamiento se coloca en el primer plano. La acción por la acción, basada en la eficacia, se me antoja extremo bastante zoológico. Parece que somos algo más que lagartija o leopardo.

Con todo, con frecuencia me viene a la mente si procedemos correctamente al separar discursos y actos. ¿Acaso se puede actuar sin cierto esquema previo de lo que vamos a hacer? Por otra parte, nuestra actividad ino influye poderosamente encima de nuestros pensamientos? ¿Circularidad indescifrable? Tanto cada sujeto humano como el colosal movimiento histórico tiran adelante, a la vez, actuando y pensando. Ni Karl Marx solo, ni tampoco Max Weber solo; ambos completándose.

13. Usted distingue tres categorias antropológicas que se dan en el ámbito de toda civilización: pregunta, posibilidad y probibición. Considera la probibición como un concepto inseparable de los conceptos de cultura, de técnica y de sociedad institucionalizada. Incluso explica "educarse es aprender las probibiciones de una civilización concreta [...], la probibición comporta irremediablemente el dolor de dejar de vivir de la necesidad e ingresar en el riesgo de poder desobedecer, siendo de tal guisa, uno, radicalmente culpable o civilizado o educado". En El pasmo de 
ser hombre usted escribe, además, que es a través de la ideología mediante la cual el Estado toma decisiones. Define que "las ideologias son pensamientos de acción; no se cuenta con una ley de educación o con una planificación educacional que no vaya orientada ideológicamente". Agrega que "los proyectos politico-económicos de la educación - una ley de educación, supongamos-, son igualmente conductas que se quiere obtener de la ciudadania", por lo que la educación nos pone ante lo que se debe ser. ¿Cuál es la función de la ley, de la norma y del imperativo en el proceso de integración del educando a la sociedad?

El resto zoológico no vive en civilización —cultura más tecnología más instituciones sociales - porque no puede ni preguntar, ni su vida consiste en posibilidad, ni tampoco las restantes bestias se descubren sometidas a prohibición. Nosotros preguntamos porque sabemos que no sabemos. El "sé que no sé nada", de Sócrates, se clava en el hontanar de lo específicamente humano. Heidegger, a quien respeto mucho intelectualmente, en su estudio Vom Wesser des Grundes (1928 y 1967) escribe: Welt ist nie, sondern Weltet —El mundo jamás está dado, el mundo se hace mundo"- El mundo no es la totalidad de cosas reales conocida de manera inconcreta, sino que es la condición para que los entes nos salgan al encuentro y esto sucede cuando nos ocupamos de - Besorgen- ellos. Preguntar es andar ocupado con el mundo. Solamente el ser humano vive de tal guisa. Interrogar nos resulta esencial. El diálogo constituye un cuestionamiento primigenio, y se dialoga en la polis y no en el monacato radical —en griego monakhos significa "Solitario". Sin otro, no hay pegunta. Sin comunidad — no escribo colectividad-el interrogante ni tan siquiera puede aflorar.

En el mismo texto, Heidegger escribe:

La realidad humana funda, instituye el mundo, en tanto únicamente que ella misma se funda en medio de lo existente. Fundar significa proyectar las propias posibilidades.

El anthropos consiste en preguntar, inquirir, examinar, interpelar. Éste es un quehacer constituyente porque no hay mundo, para nosotros, sin interrogación. La pregunta descansa sobre la necesidad de tener mundo; tal necesidad se debe a que tenemos que fundarnos en medio de lo existente. La acémila o el mico viven directamente en el mundo sin ni tan siquiera recelar del tema de la fundamentación. ¿Cómo fundamos el mundo y, a su vez, a nosotros mismos? Proyectando nuestras posibilidades. El antbropos no configura un dato y va definiéndose gracias a la capacidad de realizar sus proyectos. El potro es aquello que la zoología afirma que es. El hombre jamás queda definido; el horizonte de sus posibilidades no se clausura. El espacio donde se elaboran los proyectos es un espacio histórico, es una civilización, una vida en común siempre abierta.

Pero el extremo que especifica a no importa qué civilización histórica es la prohibición. El arkhe o principio fundamentante de toda sociedad es la interdicción, interdicción ninguna vez racionalizada del todo. Un grupo desnudo de prohibición es elemental grupo animalesco. No se da ni la prohibición del incesto entre 
los gatos o entre las mariposas o bien los cérvidos. Una sociedad humana resulta impensable sin referencia a lo prohibido; por esto han fracasado todos los intentos anarquistas de organizar un mundo humano. Prohibición o ley, sanción al transgresor y premio al sumiso, señalan los factores que organizan a una polis. Al Estado le incumbe el poder incondicional de prescribir prohibiciones, pero resulta tan vergonzoso este poder que tiene que disimularlo con ideologías. Cuenta, entonces, o que el Estado es Dios, o que representa a Dios, o bien se pone a decir que encarna la voluntad del pueblo. Ideologías a fin de disimular las obscenidades políticas y, claro está, antropológicas, porque en el fondo el ser humano, en contra de la bestia, es impudicia y deshonestidad inesquivables.

Después de lo que acabo de decirte, Sandra, entenderás que la función de la autoridad resulta imprescindible en el proceso socializador o educación como aprendizaje. De considerar la educación liberadora, el asunto se enreda, porque ya no interesa la integración social, sino que cobra importancia el hecho de vivir descle el propio acto de conciencia, fuente de libertad ante todo lo aprendido. Ahora bien, como no se hayan dado los procesos de culturalización - aprendizaje, por ejemplo, de lenguajes-, no resulta posible ni tan sólo el planteamiento de la conciencia y de la libertad, hontanares de la educación liberadora.

14. Nos bemos referido en las preguntas anteriores al bombre como biología y como sociología. Sin embargo, usted afirma que el hombre además de ser objeto - biología y sociología - es también sujeto - libertad - pero su libertad no puede ser probada, sólo se postula. Es en la libertad donde radica la educación más allá de la robotización. Sin embargo, la libertad forma parte de un discurso utópico, no científico, es algo que no se puede tocar, por lo que es posible advertir en el educando diversos niveles de intencionalidad: lo que es, lo que debe ser y lo que puede llegar a ser; entre el sentido de lo vivido y el sentido de lo que está por llegar; entre la ideologia y la utopia. Sabemos que en nuestra facticidad no podemos unir estas intencionalidades, esto sólo se logra a través de la conciencia; la conciencia, como usted mismo lo ba reconocido, permite trascender la experiencia - lo que se es-y nos abre bacia el futuro - lo que se puede ser- ¿Coincide usted con Paul Ricoeur en la posibilidad de "atestar la conciencia" a través de las mediaciones objetivadoras del lenguaje?

La libertad, que no es resultado de glándulas suprarenales, nace en el acto de conciencia, el cual es acto de alguien, en contra de lo que sostiene Sartre en La transcendance de l'ego (1937), donde intelige al acto de conciencia desprovisto de actor, como si en el espectáculo teatral hubiera acciones pero sin actores. Considero que la reflexión en torno al concepto de parole de Saussure permite afirmar el yo, el sujeto empírico.

Sigo pensando que el acto de conciencia - como erlebnis, o vivencia, y no como chose o ousia griega, sustancia- desempeña el papel mediador entre "loque-es" y "lo-que-puede-ser". Sin toma de conciencia de la circunstancia, no se origina lo posible, habiendo únicamente la pesantez del dato. 
Te respondo: mi simpatía por Ricoeur resulta indiscutible. No sólo me embruja su capacidad reflexiva, mas igualmente su talante honrado. He trabajado con él en dos Congresos de Filosofía de habla francesa y en un Seminario que la Universitat de Girona organizó sobre su libro Soi-même comme un autre dentro de la Cátedra Ferrater Mora. En 1945 Ricoeur quedó seducido por la Pbénoménologie de la perception (1945) de Merleau-Ponty; en aquel momento se pone a trabajar en una fenomenología de la acción, investigación que le permite defender su tesis de doctorado sobre la voluntad en 1950. En el primer volumen de la Encyclopédie philosophique universelle (1989) él mismo señala las caractéristicas de su filosofía. Escribe:

J'aimerais caractériser la tradition philosophique dont je me réclame par trois traits: elle est dans la ligne d'une philosophie réflexive; elle demeure dans la mouvance de la phénoménologie husserlienne; elle veut être une variante herméneutique de cette phénoménologie.

Yo llegué a la fenomenología directamente a través de Husserl, así como la hermenéutica la empecé a vivir con la obra de Gadamer. Cuando comienzo a tratar a Ricoeur, trabajaba ya con la fenomenología y con la hermenéutica, aunque por separado. La frecuentación de Ricoeur no ha logrado, de momento, que me entregue a una fenomenología hermenéutica.

Cuatro libros me han impresionado de Ricoeur. Son De l'interprétation. Essai sur Freud (1965), Temps et Récit (1983, 1984, 1985), Soi-même comme un autre (1990) y, por último, La Mémoire, l'bistoire, l'oubli (2000). El yo deja de ser mismidad invariable, convirtiéndose en identidad narrativa; es decir, construida en el cambio. El yo consciente vive de la memoria pero igualmente del proyecto, por tanto del porvenir. El relato construye juegos de lenguaje, pero asimismo estructura el tiempo al narrar, independientemente del tiempo yerto con que laboran astrónomos y físicos.

El yo ha abandonado la transparencia de Descartes, expuesta en la segunda meditación de Meditationes de prima philosophia (1641), cayéndose en la cuenta de que el yo solipsista no puede existir y que su vida es inexorablemente dialógica. El yo se descubre a sí mismo cuando dialoga. La palabra -la parole de Saussure-, en la frase y en el texto, trae a la existencia cotidiana la lengua - la langue-, contando algo acerca del mundo a quienes dialogan con nosotros. El lenguaje universal no existe; a lo sumo actúa como una idea reguladora. Desde la precariedad buscamos nuevos mundos. El contexto, inesquivable, no permite que seamos transparentemente universales. Cada conciencia vive su dolor acompañada de sufrimientos parecidos.

15. Usted ha manifestado en diversas ocasiones que el mayor interés de su trabajo consiste en inteligir la realidad educativa, ¿qué papel tiene el lenguaje en el descubrimiento de esta realidad? 
¿Qué papel desempeña el lenguaje en el proceso educativo? El libro Cours de linguistique générale (1916), que contiene los cursos que Ferdinand de Saussure impartió en Ginebra en 1907, 1908-1909, 1910 y 1911 distingue entre lengua o idioma — ruso, catalán, inglés...-, lenguaje —matemático, ético, biológico...- - y palabra - cuando yo, tú, él, hablamos. En la parole - palabra- se encuentra el momento concreto, existente, vivido. Langue y langage configuran sistemas, estructuras; en cambio, la parole se refiere al uso social de langue y de langage. La perspectiva sistémica en la línea de Von Bertalanffy - General System Theory, de 1968 - permite inteligir el lenguaje como un ordo rerum. Pero el lenguaje - entendido ahora como algo genérico- no se reduce a una asociación de sonidos y de significados; además es fenómeno social, acción humana. La parole apunta a esta segunda dimensión.

¿Qué papel desempeña el lenguaje en el proceso educativo? Vamos a ver; para que yo entienda la realidad educativa me sirvo de lenguajes en cuanto que son sistemas lingüísticos, lenguajes biológicos, psicológicos, sociológicos, históricos, tecnológicos..., y sobre ellos aplico el lenguaje filosófico en su significado de metalenguaje - una de las modalidades filosóficas-. Por otra parte, he elaborado lenguajes filosóficos metafísicos — más allá de toda posible experiencia - en los campos antropológico, axiológico y también epistemológico. Estos lenguajes han querido ser contribuciones a mejorar los hechos educativos, no ciñéndome, en esto, a la simple intelección.

Quedan por abordar aquellos lenguajes — ahora langue - que se practican en el acto de educar - en la familia, en la escuela, en la diversión...-. No es cuestión ya de inteligir lo que pasa en educación, sino de educar. Las palabras proferidas constituyen factores educantes fundamentales. Lo educativo es comunicación y el principal medio que utiliza, ésta, es el código lingüístico humano.

16. Doctor Octavi, de repente me asalta una pregunta no prevista, fuera de argumento. Es ésta: ¿valia la pena venir a la existencia?

Sí, aunque sólo fuera para formular interrogante tan turbador y largarse luego. Adivino lo que estás rumiando.

\section{7. ¿Y aquellos que sufren desoladoramente?}

Mira Sandra; el suicidio siempre será más que la nada.

18. Volviendo a lo nuestro, usted manifiesta su preocupación —Las finalidades educativas en tiempo de crisis - en "tender, aunque sea del todo imposible, hacia un modelo educativo que favorezca el desarrollo del elemento existencial del hombrem. ¿Cree que existe modelo pedagógico que logre la concientización del inviduo -o bien la educación como autoposesión-?

Sí, en el acto de educar me preocupa más la educación de Juan o de Lupita que lo que suceda a la mayoría, obtenido tal resultado, estadísticamente. El edu- 
cador - mamá, papá, profesora, profesor- no es ni pedagogo —estudioso del hecho educativo- ni tampoco político - ministro o secretario de Educación. El tecnocientífico piensa en lo general, incluso en lo universal; de igual suerte procede el político. A éste le importan los comportamientos mayoritarios y, en modo alguno, se interesa por la peripecia del sujeto singular e intransferible.

Me pides un modelo pedagógico que ilumine la educación de cada quien y no la grupal. Hablamos de modelo pedagógico; por lo tanto de paradigma, palabra griega que tomo en su significado de "modelo-modélico" o a imitar. No nos referimos a "modelo-útil", del cual hablan, por ejemplo, los físicos cuando se refieren al modelo atómico de la materia. Éstos son modelos que actúan como mediaciones a fin de entender algo. No se trata tampoco de platicar sobre un modelo didáctico que permita diseñar un sistema de intervenciones modificador de la conducta del educando. Me solicitas un modelo antropológico-pedagógico que oriente la actividad hacia el valor de la conciencia singular de cada cual. En mi manual universitario Filosofias de la educación. Paideia despliego ocho modelos antropológico-pedagógicos; el último se desarrollla bajo el epígrafe Pedagogía personalista. Éste es el modelo en cuestión.

La persona real, la de San Francesco de Assisi o de Santa Clara de Assisi, nada tiene que ver con lo universal. Francesco hubiera tenido que decir: la sencillez y la alegría no están en mí, sino que son mías. Una cosa es qué soy -mi naturalezay otra harto diferente quién soy - mi persona-. La naturaleza es lo tenido; la persona es el que tiene. Francesco fue alguien que pasó a ser algo - su biografíatenido por él. El yo de Francesco consistió en intimidad consigo mismo. Ésta es la esencia del modelo personalista.

\section{9. ¿Educar como autoposesión y educar para la libertad es lo mismo?}

Entiendo la autoposesión de alguien como la toma de conciencia, por parte de un yo empírico, de su propia vida en cuanto que vivida bic et nunc. Ni un distraído, en cuanto que distraído, ni tampoco un enajenado - especialmente el psicótico- o un drogado, aunque se trate de drogas legales. disfrutan de autoposesión. Sobreviven alterados - alter, en latín, el otro, el distinto-.

El acto de conciencia, en cuanto tal acto, me distingue y separa de todas mis vivencias. Esta fractura entre el yo que vive y el mismo yo que se da cuenta, o apercibe, de que vive, posibilita el ejercicio de la libertad. Aquel, o aquella, que tira adelante tan pegado al bulto de su existencia que no se entera de ella, jamás realizará actos de libertad convirtiéndose su biografía en una suma de secuencias prescritas. Tal es el caso del fanático --religioso, político, científico, estético, moral...-. Aquella, o aquel, que no somete a duda sus creencias - conjunto de cosas que cree, aunque éstas sean tecnocientíficas-, acaba comportándose como un robot por falta de autoposesión. Sin ésta no se dispara la libertad.

Libre de mis propias vivencias merced al acto de conciencia que tengo de ellas. Pero, ¿libre para qué? Después de años meditándolo, sólo he alcanzado a 
responder que somos libres para inyectar sentido a nuestras biografías, sentido que únicamente puede alcanzarse mediante diálogo interminable y no, por cierto, escuchando a mesías. De ser así, se puede definir la libertad como la capacidad humana de proporcionar sentido a la biografía y a la historia.

Autoposesión y libertad conceptualmente no coinciden, pero se solicitan mutuamente de manera esencial.

20. Usted señala -El pasmo de ser hombre-que "en su aqui (hic) y abora (nunc) el ser bumano reconoce su biografia como presencia, se apercibe, tiene conciencia de su vida biológica y biográfica. La esencia del acto de conciencia está en la intencionalidad" ¿Qué relación tiene su concepto con el concepto de intencionalidad de la conciencia de Husserl en las Meditaciones cartesianas?

Husserl publica Méditations cartesiennes en francés en 1931. Pero ya antes había abordado de manera coherente el tema de la intencionalidad de la conciencia en el primer libro de Ideen zu einer reinen Phänomenologie (1913). Tanto Husserl como incluso Freud siguieron las lecciones magistrales que Franz Brentano impartió en Viena. Aquí comprendió el valor de la intentio medieval para distinguir los fenómenos físicos, de los psíquicos. Para Husserl un acto será intencional cuando se refiere a algo. Cuando alguien experimenta algo, se encuentra en sí mismo con otra realidad que le sobrepasa. La conciencia intencional es fuente originaria del sentido. La conciencia queda entrelazada con aquello que se constituye.

Dígase lo que se diga, para Husserl lo que resulta indubitable es la subjetividad de la conciencia intencional. A esto se llama idealismo, cierto idealismo, ni el de Berkeley ni tampoco, claro está, el de Hegel. El propio Heidegger, discípulo de Husserl, formula este reproche a su maestro en Mein Weg in die Pbänomenologie (1963). El hecho de poner la conciencia como intencionalidad no le permite a Husserl colocar el mundo como representación en la conciencia. La realidad exterior a la conciencia, para este pensador, no tiene otra realidad que la de aparecer a la conciencia. Idealismo.

Mi concepto de intencionalidad es sin duda husserliano; ahora bien, a fin de evitar el inmanentismo subjetivista y hasta idealista, me sirvo paralelamente de la hermenéutica. Los textos los entiendo como realidades objetivas que ayudan a analizar la propia conciencia. La cuestión se enmaraña si pretendemos averiguar el origen de los relatos.

21. ¿Considera que es posible unir nuestro ser y poder ser mediante la intencionalidad del lenguaje?

La diferencia entre mi ser y mi poder-ser reside en que el primero se define por todo lo que se produce en mí que sea observable y objeto, por consiguiente, de estudios científicos. Mi poder-ser, por el contrario, resulta inagarrable no sólo por las manos - por los sentidos-, sino también por el intelecto. Mi poder-ser pende de la decisión, la cual descansa sobre la libertad, libertad que se inicia en el 
acto de conciencia. El ser humano no es únicamente sistencia - el verbo latino sistere significó "colocar"-, realidad colocada, detenida, consolidada, erigida, como las restantes cosas del mundo; además es - y esto lo destaca- ex-sistencia. La preposición latina ex señalaba el "desde". Ex-sistencia apunta al estar saliendo sin reposo de aquello que se es, lo seguro e indefectible, para ingresar en lo que todavía no se es, en lo ignoto, dudoso, vulnerable, incierto. La ex-sistencia nos convierte en trágicos; somos entes que somos lo que todavía no somos. Los análisis sartrianos del primer capítulo de la segunda parte de L'être et le néant (1943), que lleva como título Les structures immédiates du pour-soi, me impactaron el día que los leí - han transcurridos ya muchos años- y todavía en la actualidad prosiguen estimulándome.

La intencionalidad del lenguaje ¿puede unir mi ser y mi poder-ser? Según Heidegger el lenguaje es "la casa del ser", es "la domicialización de la esencia humana". Da la impresión, en consecuencia, que el habla configura el espacio donde pueden resolverse los interrogantes en torno al hombre. El lenguaje posibilita una hermenéutica trascendental del antbropos interpretando la inteligencia comunicativa de éste y asimismo la inteligencia que el hombre procura de sí mismo. Platón hizo notar en el Sophistes e Peri tou ontos que "el pensamiento es el diálogo, sin sonidos, del alma consigo misma" — 263, d.

El lenguaje presenta dos funciones: la de representación del mundo y la de comunicación entre congéneres. La primera función produce sistemas sintácticosemánticos; la segunda, en cambio, se refiere a la competencia pragmática universal. A esta dimensión pragmática, comunicativa, dialógica, del lenguaje, ¿qué intencionalidad la atraviesa? Sócrates, el de los primeros diálogos platónicos, se resiste a reducir el diálogo a técnicas retóricas. El diálogo va más allá esforzándose en liberar al ser humano de sus inmediateces -el ser-, dándole acceso al Bien - Agatbon-, condición de una vida moral y ciudadana que no se destruya a sí misma - el poder-ser- En el habla dialógica descubro la intencionalidad que permite conectar ser y poder-ser humanos.

22. ¿Considera que la novela narrativa - o los relatos miticos-pueden certificar la relación entre noesis y noema a través de la intencionalidad del lenguaje?

Al pronto me asalta una preocupación de bulto: ¿¿cómo el lenguaje puede ser estudiado por el lenguaje? Sólo contamos con el recurso al metalenguaje. Ahora bien, esto supone que no existe el lenguaje universal habiendo únicamente lenguajes regionales. Desde un lenguaje analizamos otro. La Verdad, así, queda enterrada. Sobreviven tan sólo verdades. Y todavía otras inquietudes: ¿qué relación se establece entre lenguaje y mundo?, ¿cómo es posible la significación lingüística?, ¿cómo esclarecer las relaciones medievales entre signans — significante-, signatum — significado- y denotatum — referente —? Tú, Sandra, preguntas por el relato mítico, pero, claro, también éste queda tocado por los cuestionamientos anteriores. 
El mito es un mensaje presentado en forma de narración, mediante el cual una colectividad humana transmite de generación en generación aquello que resulta imprescindible guardar en la memoria porque encierra un pasado iluminador de todo presente y hasta de todo futuro. El mito salvaguarda al grupo. Ésta, por lo menos, es su función.

El relato responde a la estructura histórica del hombre. No contamos con Historia universal, sino con un sinnúmero de historias, de suyo inacabadas. El tiempo del relato no es independiente, del todo, ni del tiempo real del suceso, ni tampoco de la temporalidad del lector. En el primer volumen de Temps et récit (1983) Ricoeur escribe:

Le temps devient temps humain dans la mesure où il est articulé sur un mode narratif, et le récit atteint sa signification plénière quand il devient une condition de l'expérience temporelle.

Tiempo y relato se relacionan a través de la acción humana cuando ésta viene narrada. No interesa para el caso ni el orden sintáctico, ni el orden semántico, del lenguaje, sino el orden pragmático, incluidos los enunciados performativos. Pero, ¿qué es el mundo con respecto a la conciencia que tenemos de él?, responde Husserl en el primer libro de Ideen (1913):

La naturaleza sólo es posible como unidad intencional de la conciencia... La naturaleza se manifiesta como correlato de la conciencia.

Los objetos se constituyen, siguiendo a Husserl, merced a la sedimentación de significaciones. En el hontanar de tales sedimentaciones se coloca la Glaube-fe-, la creencia, anterior al saber propiamente tal. Lo que se muestra acaba, de tal suerte, reducido a cómo se muestra. Nos encontramos ya, Sandra, en el corazón de tu cuestión, un tanto compleja. La unidad del sujeto es precisamente, genética, narrable por tanto. En Méditations cartésiennes (1931) se lee:

El ego se constituye en la unidad de una historia.

El yo, así configurado, realiza el análisis fenomenológico en dos direcciones, la noética - noesis - y la noemática - noema - La noesis constituye el momento de la conciencia en el cual, ésta, proporciona sentido; la noesis es la esencia del acto de pensar. El noema, en cambio, es el correlato del acto de conciencia, es un instante de la vida intencional de la conciencia y forma parte de las vivencias de ésta.

Las narraciones míticas no describen el mundo; son noemas secuenciados que arrancan de la noesis intencional objetivada, al fin, lingüisticamente.

23. Paul Ricoeur escribe en su Autocomprensión e Historia que "la comprensión de si es una narrativa de un extremo a otro. Comprenderse es apropiarse de la bistoria de la propia vida de uno. Abora bien, comprender esta bistoria es hacer el relato 
de ella, conducida por los relatos, tanto bistóricos como ficticios, que bemos comprendido y amado. Es asi como nos hacemos lectores de nuestra propia vida". Dentro de su extensa obra usted escribió una trilogia - novela narrativa- La novela narrativa involucra mültiples similitudes entre El Profesor y aspectos especificos de su propia vida (El Profesor da clases de Filosofía en la Universidad Autónoma de Barcelona, los alumnos con que se reúne tienen los mismos nombres de los alumnos que usted tuvo en esa temporada, los viajes que El Profesor realizó corresponden a los viajes que usted también ba realizado, los amigos de El Profesor son también amigos suyos - Jassans, el profesor de Grecia, la compañera que tuvo durante sus estudios en Paris, etc.) - ¿Acepta usted la posibilidad del entrelazamiento y descentramiento de sus propias experiencias - puestas en boca de los personajes que viven situaciones conflictivas que también se pueden advertir en su propia biografia- a través de la novela narrativa?

¿Acepta, usted, entrelazamiento y descentramiento de sus propias experiencias a través de su trilogía de ensayos novelados? Esta demanda me fuerza a realizar una incursión por tierras de mi inconsciente. No obstante, no me atrevo, porque no domino, ni con mucho, las técnicas psicoanalíticas, que por si fuera poco tendría que poner en práctica yo. Para responderte me resulta más fácil aquel análisis filosófico que procura inteligir qué sea la persona, esta intimidad persistente que nos insufla seguridad y firmeza, tan indispensables, una y otra, para no desesperar.

La única forma de acceder al quién de la existencia singular consiste en valerse del relato de las acciones realizadas por el supuesto yo. El yo actor de una biografía se ha referido, se refiere y continuará refiriéndose - hasta pararse en la definitoria, in hora mortis - a sí mismo, a los otros y a la circunstancia. La vida es definitiva hasta que se abraza lo definitivo y deja en aquel momento de haber vida. Mi existencia ha tenido sentido y prosigue teniéndolo en la medida en que me he tratado a mí mismo, a los prójimos y al mundo. La existencia -Dasein-, de fiarnos de Sein und Zeit (1927) de Heidegger, consiste en sein in der Welt - mundo como Umwelt - y también en Mit-sein, "ser-con". He sido yo gracias al entorno. Mi yo resulta ininteligible sin una suma de experiencias. Mi persona únicamente se me hace presente renovando la retentiva y poniéndome a vivir expectante. No soy sólo un ente arrojado; también consisto en proyecto. Entre lo primero y lo segundo se estira la obra de mi vida hasta el ahora en que sigo todavía vivo. La caída del telón clausurará toda expectativa.

Mi obra escrita también deja ver al yo. Mis libros narrativos - la trilogíasupongo que permiten vislumbrar mi persona aunque sea entre velos traslúcidos. El hablar y el escribir hacen posible que los demás me conozcan. El habla personal deja casi al desnudo al secreto de vivir. El óbito proporcionará, por último, sentido absoluto a mi yo. El cadáver no habla, no comunica, guarda silencio aun en el supuesto de que lo insulten.

La trilogía sobre Eulalia es un esfuerzo de anamnesis individual y quedó redactada con el desespero de buscarle sentido tanto a la biografía como asimismo a la 
historia. No quedando satisfecho con los aconteceres intramundanos, se indaga el más allá de los mismos. No quiero cargar con mi vida como si se tratara de un bulto; quiero aceptarla con alegría. Pero no es, ésta, faena llana ni agradable.

Mi trilogía, Sandra, creo que se sitúa a mitad de camino entre novel y romance - terminología anglosajona en la obra narrativa-, a mitad de camino entre mímesis e imaginación. Utilizo el género literario con ánimo de poner luz a hechos no literarios. El libro Mensonge romantique et vérité romanesque (1961) de René Girard puede resultar útil en vistas a desnudar mis tres textos.

Puesto a responder a tu preciso interrogatorio, me inclino por decirte que sí, que aciertas, teniendo presente, faltaba más, cuanto acabo de comentarte.

24. La pregunta que guía todo el recorrido de la obra surge de El Profesor que, al considerarse enfermo de ignorancia, decide investigar "¿hacia dónde se dirige el tiempo de los hombres?." Usted hace una clara distinción entre tiempo biográfico —existencia_y tiempo histórico — esencia_. ¿Es el pretérito, el presente, el futuro, o el éxtasis de los tres tiempos lo que permite dar sentido al bombre?

Pretérito, presente y futuro, ¿permiten dar sentido al ser humano? Te respondo escuetamente, de forma pelada, frugal diría.

Los brutos no humanos disponen de retentiva - manera de que no se escape, del todo, el pretérito- y de sensaciones y respuestas - formas de agarrarse al presente- Pero ipor ventura el zoon mira hacia el futuro?; a lo sumo lo mira como aguardo —el gato aguardando con sus músculos que salga el ratoncillo de su escondrijo--, pero jamás como espera - espera en tiempos mejores-y menos todavía a modo de esperanza — salto desde el tiempo al "fuera-tiempo"-.

El ser humano es un animal que se especifica por vivir en función del porvenir. Ahora bien, la tensión "pretérito-presente-futuro" plantea solamente la cuestión del sentido, pero jamás entrega el sentido. Éste espera indefectiblemente en el horizonte inalcanzable. El anthropos se desvive por el significado de la existencia, pero no está a su alcance el abrazarlo. Por lo menos en el útero del proceso histórico.

25. De repente me asalta una pregunta no prevista, fuera de argumento. Es ésta: ¿valia la pena venir a la existencia?

Sí, aunque sólo fuera para formular interrogante tan turbador y largarse luego. Adivino lo que estás rumiando. ¿Y aquellos que sufren desoladoramente? Mira Sandra, el suicidio siempre será más que la nada.

26. En su libro El pasmo de hombre usted hace una introducción en la que se reconoce "codificado socialmente". Señala: "Yo era un cenobita más del espacio civilizado - ¿2- de Barcelona o, si se me apura, de un espacio algo más extenso que abarcaría confusamente lo que Ilaman peninsula Ibérica y bexágono francés [...] Era yo, pues, un pedazo de vida común; era: gente, masa, muchedumbre, público, pueblo, vecindario. Vulgo. Sin percatarme, como cualquier otro cenobita me habia 
convertido en tîtere, fantoche, espantajo... pendiente de mi pais so capa de ser animal social... Mi biografia se reducia a ser alteración - no ser yo, sino lo otro, alterum-, se ceñia a ser sobresalto, excitación y trastorno; andaba, como todos, descompuesto, cambiado, agitado, sofocado [...] No soy de aquellos que creen que en cuanto más socializado, uno, tanto más humano; no. Lo mio es no pertenecer a los animalia mixta, sino ser animal propio [...] Opté por desérere, por abandonar, por huir, por separarme, por irme al desierto. Comencé un anábasis o expedición hacia el interior. Busqué el recato, el retraimiento y recogimiento. Me aparté a fin de descodificarme socialmente - dentro de lo posible-.. ¿Puede equipararse esta definición con lo que usted identifica como educación como learning?

Sobre este particular, mi respuesta es decidida. Sí. Se trata de una descripción, más o menos literaria, de la educación como learning.

27. Paul Ricoeur en su libro Sí mismo como otro define dos términos de la identidad: identidad como idem e identidad como ipse. Tengo entendido que Ricoeur ha sido un punto de referencia en su obra, por lo que omito la definición que Ricoeur da a estos dos tipos de identidad. Mi pregunta es: jexiste la posibilidad de igualar lo que usted identifica como "educación para la robotización" con la definición de la mismidad —o permanencia a través del tiempo-que bace Ricoeur?

Soi-même comme un autre (1990) es el resultado de las Gifford lectures que pronunció Ricoeur en la Universidad de Edimbourg. En el libro retoma los grandes temas de su trayectoria; a partir de la noción je peux recuerda el je peux parler —análisis del lenguaje-, el je peux agir - estudios sobre la voluntat y la acción-, y queda abierto al siguiente libro, Temps et Récit, con el je peux raconter. Además no pierde de vista el je suis imputable -ética y política - con que cierra sus vastas temáticas. En Soi-même comme un autre aborda al sujeto humano distinguiendo la figura de la mêmeté, merced a la cual un sujeto dura a lo largo del tiempo, y la figura de la ipséité, por la cual el sujeto es una singularidad irrepetible y solitaria. Su enfoque quiere escapar tanto del ego cogito cartesiano, un yo soberano y seguro, como del sujeto considerado por Nietzsche, un yo múltiple y humillado que deja de ser hontanar de verdad. Ricoeur vuelve al soi-même pero se trata de un movimiento hacia soi-même comme un autre. El yo al que regresa ha perdido el esplendor y la claridad de Descartes siendo un sí mismo rodeado de tinieblas, pero evita caer en la conciencia desmoralizada de Heidegger - sin moral porque sólo hay tiempo-. Para Ricoeur, en cambio, la conciencia llama silenciosamente no perdiéndose, así, la ética. Con todo, el sujeto es vulnerable.

Yo distingo entre la educación que forma robots y la educación que procura engendrar personas en autoposesión. El educado por la primera educación es un alterado, un individuo, o unidad psicosomática, programado por el código genético y reprogramado por el código social. Por el contrario, el educado por la educación liberadora es un ensimismado o alguien en posesión de sí; este tal se pone a vivir desde el futuro, desde las utopías. Este segundo es persona — para mí, 
persona no es algo, sino personalización, proceso-. El primer educado, el robótico, no supera el status de individuo, de unidad psicosomática, que es, por ejemplo, la de este murciélago que arranca el vuelo al iniciarse la oscuridad. El educado alterado o robótico y el educado ensimismado o en autoposesión constituyen dos paradigmas extremos que permiten una gama amplia de actividad entre uno y otro. Se trata de imágenes que facilitan la comprensión de lo que se lleva entre manos en una tarea educante concreta.

¿Pueden establecerse analogías entre même y educado robot? Sin duda alguna. Lo mismo respondería con respecto a ipse y educado ensimismado. Ahora bien, Sandra, yo no he realizado dicha comparación, aunque descubro una buena hipótesis en este asunto.

28. Usted se ha preguntado en otras ocasiones "¿por qué educando y educadores ambicionan lo otro, lo tan otro, que deja ya de ser educación?", ¿es posible equiparar lo que usted identifica como educar para la autoposesión con la definición de ipseidad de Paul Ricoeur?

Aquí sí que puedo responderte categóricamente. La ipseidad de Ricoeur encaja con mi educar para la autoposesión.

29. La trilogía - novela narrativa - termina con el "fracaso" de El Profesor - al no encontrar la respuesta a su pregunta - El Profesor, pues, queda suspendido en la esperanza. Sin embargo, en su obra Els valors d'Occident usted se remite a la interpretación de las obras la Eneida, el Génesis y la Odisea. ¿Considera que la posibilidad de encontrar el sentido del hombre radica en el pasado?

Sí, el profesor fracasa. La razón fracasa. La Ilustración no nos ha salvado. La obra Dialektik der Aufklärung (1947) de Adorno y de Horkheimer fuerza a pensar sobre los peligros de la razón. La dirección que anima mis últimos trabajos —entre los cuales destaca, de momento, Els valors d'Occident - intenta destacar el nudo que nos dejó Eulalia con su fallecimiento. ¿Puede el simple testimonio de una vida dar respuesta a la pregunta sobre si hay que ser morales?; no atino a ver cómo unas acciones honradas puedan valer ante un interrogante que se dirige al intelecto. ¿De qué razones disponemos para tener que ser buenos? Nietzsche nos abandonó huérfanos; escribe en Götterdämmerung - 1888, publicado en 1889-que la Verdad es la gran mentira que nos ha dejado la Razón, "vieja hembra engañosa".

La hermenéutica de Gadamer me ha ayudado a replantear el asunto. Wabrbeit und Methode. Grundzüge einer philosophischen Hermeneutik (1960), unos capítulos más que otros, es una obra que me ha asistido. Arranco del supuesto que no existe ni el lenguaje universal ni tampoco la lengua universal. Menos todavía se da, claro está, la parole ilimitada. ¿Cómo plantearse los valores antropológicos universales o los Droits de l'bomme et du citoyen -la trágico-cómica Révolution française elaboró en pocos años tres Déclarations, la de 1789, la de 1793 y la 1795-? Ante perspectiva tan angosta he estimado cuerdo ceñirme a los lenguajes y lenguas de 
Occidente, donde se han producido escritos considerables en torno al extremo que me alarma. Nuestra memoria colectiva, que en modo alguno resulta ecuménica, se ha forjado viviendo con sangre, aunque tampoco le han faltado momentos de diástole. En el primer origen, Torah -Jerusalén-, Odysseia - Atenas- y Aeneida -Romainician nuestra memoria de occidentales; después, a partir del I Concilio de Efeso (325), el cristianismo sintetiza culturalmente la dialéctica entre la profecía, o el valor del sentido, y la tecnociencia o valor del saber y de la eficacia. En el Renacimiento comienza a desintegrarse la síntesis cristiana revalorizándose únicamente razón científica y razón técnica. Con Nietzsche fallece incluso la Razón.

¿Qué hacer? Los escritos de Occidente objetivan y sedimentan siglos y siglos de búsqueda de sentido del proceso histórico dentro de un espacio geográfico preciso que se ha ido ampliando al continente americano, a Australia, a Nueva Zelanda. Con los siglos se ha dibujado una persistencia axiológica que finalmente nos alcanza. Millones de antepasados viviendo el cuestionamiento del para qué seguir. Los escritores han objetivado las ansias y las esperanzas de millones de gentes. Parece sensato sostener que los valores que han tirado adelante se han vuelto para nosotros, occidentales, valores respetables. La lista axiológica no queda cerrada, pero sí que está ahí, redactada, y nos solicita. No queda probada la obligación moral, pero hay que reconocer que una historia milenaria de sufrimientos y de esperas resulta más honorable que la votación que unos iletrados hacen en un parlamento - los políticos no leen; se creen semidioses por aquella ideología, que les va tan bien, que dice que ellos representan al pueblo.

No. El sentido no se esconde en el pasado. No se oculta detrás de tiempo alguno. El sentido es lo que averiguamos sin tomarnos descanso. Esto sí, con esperanza aunque ésta no sea la teologal. Lo que sucede es que para dialogar en torno al significado de lo antropológico no es cuestión de comenzar a partir de cero, como si el fenómeno humano fuera cosa de este momento y no añeja de milenios en nuestra cuenca mediterránea. Nos duele el presente porque avanza ciego; por tal motivo leemos el pretérito — trabajo de anamnesis- a fin de que, comentándolo, nos ilumine en las urgencias actuales y esto se lleva a cabo, inexorablemente, con ánimo de producir sentidos, o legitimaciones, del existir que, de momento, sosieguen el ansia de vivir sensatamente - referencia a la phronesis de que habla Aristóteles en su Ta meta ta pbysika.

30. En la misma obra, Els valors d'Occident, usted se remite a un triángulo antropológico que simboliza las culturas, griega, romana y bebrea, y al cual accede mediante la interpretación de las narraciones míticas, la Eneida, el Génesis y la Odisea, a fin de intelegir los valores del mundo occidental. ¿Cree que es posible obtener de esta obra un modelo universal de valores?

No. Contundentemente no. Las gentes del mediterráneo formulan interrogantes y proporcionan respuestas que no descubrimos, por ejemplo, en la civilización brahmánica - Vedismo y Vedanta-. Lo mismo diría en lo tocante al confucionismo 
y al neoconfucionismo chinos; se trata de comprensiones producidas aparte. El papanatismo, el esnobismo y la ganancia económica han imaginado puentes entre orillas mojadas por mares distintos. El ecumenismo, el todos somos lo mismo, o bien es desfachatez dictatorial que así disimula su desafuero, o bien se trata de parvulez e incluso de necedad. Se trata de gentes que han leído muy poco y mal.

No atino a ver de qué manera pueden obtenerse los valores universales. Hasta el presente los valores han sido propios de una civilización concreta. Así, los valores del Islam no coinciden ni con los cristianos ni tampoco con los brahmánicos. Por otra parte, afirmar que los valores propios son universales constituye una megalomanía morbosa. Habermas en los dos volúmenes de Theorie des Kommunikativen Handelns (1981) manifiesta la pretensión universalista de la pragmática lingüística, pero no puede fundamentarlo. Por esta razón Apel, ya en Transformation der Pbilosophie (1973), imitando a Kant, pretende fundamentar a priori las proposiciones axiológicas.

Yo prefiero quedarme con Occidente y con Gadamer. ¿Por qué?, lo estimo más sensato y más a pedir de mano. Los universalismos huyen de lo real concreto, le temen al hombre de carne y hueso, de que escribió Unamuno. Los universalistas acostumbran a ser cobardes, como los pacifistas.

31. En diversas ocasiones usted ba manifestado inconformidad con la educación, en Occidente, que carece de valores "universales y necesarios". Sin embargo en 1996 usted publicó el libro Las finalidades educativas en tiempo de crisis en cuyo apartado final usted propone unos fines estilizados. ¿Considera vigentes los fines a que apunta - placer sensorial, progreso utópico, aceptación de los límites, comunicación entre próximos, buida artística, esperanza en lo absoluto, duda creadora, ironía socrática, ignorancia sapiencial y talante ético individual-?

Mi formación universitaria, en plena dictadura del general Franco, fue escolástica. El programa de la carrera de filosofía terminaba la historia del pensamiento filosófico con Hegel. Significativo. Mi vuelco intelectual se produce en París durante el curso 1970-1971 cuando disfrutando de una excelente beca del Gobierno francés estudio con Michel Foucault, con Levi-Strauss, con Wahl y con Vuillemin. Te cuento esto, Sandra, porque así te das cuenta de mi primer discurso filosófico que fundamentaba metafísicamente - ens, unum, bonum atque pulchrum convertuntur - los valores éticos. El libro Finalidades educativas en tiempo de crisis - que por cierto publico en 1982 - representa una protesta contra el escolasticismo, en el que me formaron, aunque no atino entonces en argumentar seriamente mi propuesta. Era más una patada o una coz que una argumentación fina.

¿Aceptaría ahora yo aquellos fines estilizados? Pues, sí. A condición de considerarlos provisionales y a modo de salidas de urgencia en una sociedad abrumada y aturdida. 


\section{2. ¿Cuáles son los valores que usted considera que debe baber en educación?}

Te remito al Epíleg sobre els nostres valors, de mi libro Els valors d'Occident (2001) y al capítulo octavo, El compromiso, de mi última obra, El siglo postmoderno -Ed. Crítica, Barcelona, 2002-.

Pero añado algo pensando en educadores y educandos. Padecemos el acoso y el apremio de mesías y salvadores variopintos -eclesiásticos, políticos, sindicalistas, artistas, científicos, tecnólogos, visionarios de todo pelaje...-, todos nos aseguran que poseen el secreto, el brebaje intelectual, que nos hará buenos y felices. Estos charlatanes han llenado la historia de Occidente; no es, por tanto, proceder sólo actual. Ante tantos contenidos salvíficos - hay que hacer esto o lo otro; pensar de tal guisa y no de forma distinta- se me ocurre que el valor primigenio no es otro que el de tomar conciencia de cuanto se nos cuenta y de cuanto vivimos, para, de tal suerte, quedar separados de tantas y tan grandes monsergas y mogigangas. Para empezar es necesario vivir de la duda y en la soledad íntima. ¿Que el infante no puede todavía vivir en tal desamparo existencial?, pues se aguarda el tiempo propicio. Pero, antes de digerir valores mostrencos, hay que comenzar siendo uno mismo. Éste es el valor hontanar de toda vida humana singular. Duda, ironía, silencio, retraimiento, y toma de conciencia de cuanto me rodea; es decir, debe ser cada cual un ojo sobre la circunstancia. Sólo después, ayudados por el diálogo, decidiremos los valores. Igual, también, acabamos aceptando los de un charlatán, pero por lo menos, antes, me habré reído de sus ocurrencias, las que sean. Sin sentido del humor no se da el ser humano. Ninguna acémila ríe cuando le cuentan un chiste, o una doctrina moral o estética o científica. Escuchan todo esto con talante imperturbable. El primer valor del proceso educativo está en enterarse que uno no se confunde con su circunstancia.

33. Aranguren escribe en Crítica y meditación que volver la vista atrás mueve casi siempre a la nostalgia, o a la autocrítica, o a ambas cosas; es como la despedida de lo que se ha sido basta entonces y el comienzo de lo que se dispone entonces a ser, para volver a cambiar una y otra vez. Los retornos significan unas veces la conclusión de una etapa en la secuencia de la vida, para el inicio de otra, o bien la conclusión pura y simple de la vida, de la vida intelectual y vitalmente activa.. La autobiografía que se publicó en la Revista Anthropos manifiesta que usted ba estado en constante confrontación con sus propios esquemas. En Mis fragilidades de existir pensando usted escribe que "no resulta fácil desprenderse de un pedazo constitutivo de las creencias de uno. En el fondo, no poseemos creencias, sino que éstas nos tienen a nosotros constituyendo la columna vertebral de nuestras vidas". ¿Considera que ba babido etapas de su vida que le ban puesto ante la tensión entre lo que usted quiere realizar y lo que las instituciones -llamémosle Estado, familia, religión, etc.- le piden y cómo ello ba afectado el sentido de su propia vida? 
El que acabas de plantearme, Sandra, es asunto más arduo de lo que parece al primer pronto. Claro que tú no preguntas directamente por este negocio en general, sino que inquieres cómo me ha ido, en la vida, la faena de desenredarlo o, por ventura, disiparlo. Te refieres a la tensión entre el yo, de cada quien, y las instituciones en las cuales prevalece inexorablemente el sistema por encima de las singularidades. Tu interrogante apunta abiertamente a la agonía -en griego agon fue competición, combate, guerra - entre lo singular y concreto - una biografía, por ejemplo, de carne y hueso-, por un lado, y el sistema - una sociedad histórica, supongamos-. Mi vida como igualmente toda vida que se resiste a desaparecer, en tanto que singularidad, no puede menos que constituirse en polemos, en bellum, entre su yo consciente y la estructura social en la que está inserto. La confrontación entre ambos extremos solamente muere con la muerte del yo.

Albert Camus plantea el tema agónico del ser humano en la pieza de teatro Les Justes (1950). Kaliayev ama a Dora e igualmente a la inocencia de los pequeños sobrinos del Gran Duque de Moscú. Por este último motivo no tira la bomba contra el carruaje. Cuando la institución le pide cuentas por no haber obedecido, responde gritando:

Yo amo a los que viven hoy en la misma tierra que yo... Por ellos lucho y consiento en morir. Por una ciudad lejana, de la que además no estoy seguro, no iré a golpear el rostro de mis hermanos.

Hegel en su obra mayúscula Pbänomenologie des Geistes (1807) defiende la resolución del conflicto entre la conciencia de sí — subjetividad-y la conciencia de todos —objetividad. Imagina la reconciliación entre ambos opuestos en la última parte, la VIII, donde trata del Saber absoluto. Así como el yo divino, Jesús, muere y resucita luego en la comunidad, así también el yo singular morirá en provecho de un nosotros universal. La misión de cada cual no es otra que la de llevar, algo más adelante, el peso del Espíritu.

Sandra, he preferido la tragedia del existencialismo antes que la reconciliación del idealismo hegeliano. Me niego a renunciar a la vida de mi yo. Y ¿qué pasó en la cotidianidad de la biografía ante tal tesitura mía?, me enfrenté con las autoridades institucionales. He tenido conflictos con la jerarquía eclesiástica —no toleré la omnisciencia pontificia negándome, en consecuencia, a la censura de mis escritos-; he sostenido batallas con las autoridades académicas, rector de la Universidad de Barcelona y ministro de Educación del General Franco, por no someterme a la orden de no enseñar el existencialismo, el marxismo y el anarquismo en el aula universitaria. La policía política se ocupó de mí. Una institución, sin embargo, tuve siempre al lado, fue mi familia. Tales peripecias ¿han afectado mi personal vida?; te respondo que, más que afectarla, la han efectuado, realizado, producido. No atino a separar mi biografía y mis luchas. Sospecho, no obstante, que esto es así en todas las vidas humanas conscientes. 
SANDRA LILIA GÁLVEZ DE RUDZKI

ENTREVISTA A OCTAVI FULLAT

\section{4. ¿Volvería a escribir una novela narrativa?}

¿Redactaría yo otro ensayo novelado? Por un lado, debo confesar cierta repugnancia, porque no me considero en posesión de habilidades literarias, pero, por otro lado, me atrae el proyecto, porque mi talante más existencialista que sistemático, como te subrayaba en tu pregunta anterior, me lleva a utilizar un procedimiento más apto para salvar al yo de cada quien.

35. Dr. Octavi, tengo entendido que actualmente está trabajando en una obra densa. ¿Cuál de las tres lineas que usted más ha desarrollado es en la que se involucra -epistemología, antropología o axiologia-?

Sí, estoy laborando en una obra vasta, de la que han aparecido ya ideas más o menos puntuales en libros y revistas. Sospecho que con unas mil páginas lograré cerrar mi ambición: ofrecer unos valores respetables para Occidente, valores que valen porque constituyen la objetivación de lágrimas, de sangre y también de goces fugaces de millones de seres humanos que han buscado un sentido sensato de la historia, sentido que inyecte coraje hacia el porvenir. ¿Se trata, en dicha obra, de epistemología o de antropología o acaso de axiología? Si las garras de la noche no lo impiden, será antropología axiológica.

36. Por último, Dr. Octavi, esta obra en que trabaja al presente, ¿puede poner luz a problemas acuciantes actuales como es el caso del terrorismo globalizado?

Ciertamente, la globalización no afecta únicamente a las áreas económica y cultural; igualmente se ha expandido a la esfera del crimen. La política del caos, que se manifestó sin ambigüedades el 11 de septiembre del 2001, ha puesto sobre el tapete la mundialización del nihilismo frente a unas sociedades estructuradas en forma de Estados, que van perdiendo soberanía y que no pueden ya sostener la seguridad de los ciudadanos, en contra del pacto social imaginado por Hobbes en el Leviathan. Las sociedades democráticas son las más vulnerables porque en ellas ya casi nada queda prohibido, y sin prohibición desaparece la sociedad.

El ámbito que investigo ¿qué me insinúa sobre el particular? Si acepto la metodología de Max Weber - tanto en L'éthique protestante et l'esprit du capitalisme, según la versión francesa, como en su obra póstuma Gesammelte Aufsätze zur Wissenschaftslebre, de 1922-, si acepto, decía, la metodología weberiana me asalta una hipótesis de investigación paralela a la tarea que ahora llevo entre manos. Es la siguiente. Las Weltanschauungen con religiones monoteístas -un solo dios y, además, personal- se objetivan históricamente en formas dominantes y, a la vez, excluyentes. Guerra santa, cruzada, ejército de Dios. Además evolucionan con máxima dificultad. Tienden a encerrarse sobre sí mismas. Poseen la verdad y la bondad de la historia; el resto de la humanidad vive en el error y en la maldad. El dios único sale garante de ellos. 
Las religiones de divinidad imprecisa y despersonalizada -Dios es algo, no alguien - , caso del brahmanismo, del confucionismo, del sintoísmo, del budismo..., al no tener una dogmática clara y clausurada, resultan más acomodaticias y dialogantes. Los politeísmos poseen igualmente un credo polimorfo y versátil.

El cristianismo ofrece una originalidad que lo coloca aparte. Siendo la síntesis histórica del monoteísmo judío y del paganismo grecorromano, su objetivación en la historia resulta ambigua ofreciendo alternativamente rostro dictatorial y rostro fraterno. Si, por otra parte, nos damos cuenta de que a partir del Renacimiento la dilogía cristiana comienza a deshacerse en provecho del paganismo tecnocientífico grecorromano, y caemos igualmente en la cuenta que después de Nietzsche el cristianismo ha muerto sociológicamente, entonces no hay que contar con él para mi hipótesis. Su fuerza social residual descansa ahora sobre el poder económico.

A fin de explicar la actual globalización del terror nos quedan únicamente el judaísmo y el islam. Ambos igualmente intransigentes porque ambos hablan y actúan porque el Dios absoluto se encarna aliquo modo en ellos. Dado que sólo hay 14 millones de judíos frente a 1.127 millones de musulmanes, queda claro, a pesar del dinero de los primeros, que el único grupo a tener presente en mi hipótesis antropológica es el islam.

Bueno, Sandra, es cuestión tan sólo de una hipótesis sugerida por mis estudios actuales, hipótesis que yo no trabajo ya que me ocupo solamente de averiguar la axiología de Occidente. Igual se trata de una hipótesis planteada atropelladamente y, por tanto, sin futuro. Ignoro si un día me quedará tiempo para abordarla. Confieso que me tienta, pero pide demasiados años para mi edad; ya sabes, yo soy provectae aetatis — de edad avanzada-. 